\title{
A Review on Landfill Management in the Utilization of Plastic Waste as an Alternative Fuel
}

\author{
Nurul Hidayah ${ }^{1, *}$ and Syafrudin ${ }^{1,2}$ \\ ${ }^{1}$ Master Program of Environmental Science, School of Post Graduate Studies, Diponegoro University - Indonesia \\ ${ }^{2}$ Environmental Engineering Dept, Faculty of Engineering, Diponegoro University - Indonesia
}

\begin{abstract}
Wastes from landfills originate from many spheres of life. These are produces as a result of human activities either domestically or industrially. The global plastic production increased over years due to the vast applications of plastics in many sectors. The continuous demand of plastics caused the plastic wastes accumulation in the landfill consumed a lot of spaces that contributed to the environmental. In addition, economic growth and development also increased our demand and dependency on plastics which leads to its accumulation in landfills imposing risk on human health, animals and cause environmental pollution problems such as ground water contamination, sanitary related issues, etc. The management and disposal of plastic waste have become a major concern, especially in developing cities. The idea of waste to energy recovery is one of the promising techniques used for managing the waste of plastic. Hence, this paper aims review at utilizing of plastic as an alternative fuel.
\end{abstract}

\section{Introduction}

The rising environmental problems, involving greenhouse gases and air and water pollution together with the energy crisis and resource scarcity will become more imminent in the coming decades, dictating that we need to take actions towards a more sustainable society. Energy are mainly produced by using fossil resources which causes the release of $\mathrm{CO}_{2}$ in the atmosphere together with other toxic compounds (such as volatile organic compounds and nitrogen oxides). It is estimated that $90 \%$ of the global emission in $\mathrm{CO}_{2}$ (which reached approximately 34 billion tons of greenhouse gases in 2011) was derived from the combustion of fossil fuels [1]. Important challenge is the rising accumulation of wastes in the environment. The waste accumulation in the environment has raised the public awareness due to the problems the amount disposed into the environment causes. On the other hand, the huge volumes that are produced globally alongside with the diversity that these waste present makes them ideal candidates to be used for high value applications [2].

Conventional methods that are widely used for the treatment and management of municipal solid waste (MSW) include, landfilling, incineration, composting, etc., present some negative characteristics. Waste disposal by landfilling cause severe environmental issues such as uncontrolled release of methane in the atmosphere, a gas that has 20 to 23 times higher GHG (greenhouse gas) potential than $\mathrm{CO}_{2}$, production of leachate which contaminates the soil and the ground water, unpleasant odors and spread of pathogenic microorganisms [3]. For example, more than $95 \%$ of food waste (FW - estimated to be between $25 \%$ and $70 \%$ of MSW) are ending up in landfills, which has a catastrophic impact on the climate due to the release of methane and other GHGs (which is calculated to be 125 $\mathrm{m}^{3}$ of gas per ton of land filled FW) [4]. Nevertheless, the potential of wastes such as a plastic to produce valuable fuels is an attractive alternative solution that has gain the interest of both scientific and public opinion [5].

Waste management, i.e., the collection, transport, recovery and neutralization of waste, as well as the supervision of these activities and the locations where the waste is neutralized, are among the most important issues in terms of environmental protection. The importance of waste management continues to grow due to the progress of civilization and the increase in waste quantity [6]. Rapid and unplanned urbanization leaves municipalities largely overwhelmed when it comes to the collection and disposal of increasing amounts of waste. Municipal solid waste management continues to remain one of the most neglected areas of urban development and this has called for sustainable means of management. It is characterized by a number of waste types and of these are plastic solid wastes (PSW) [7]. Currently, various forms of plastics are used around the world. Large amounts of plastic are used in packing films, wrapping materials, shopping and garbage bags, fluid containers, toys, household industrial products and building material. However, the benefits of plastic use are suppressed by its harmful impacts on the

*Corresponding author: nurul.hida1@gmail.com 
environment. Plastics are a small but significant component of waste streams [8].

The invention of plastics is a major milestone that led to improvement in the quality of the lives of human beings. Since its first synthesis in early 1900 s, plastics have substituted many types of materials such as wood, metals and ceramics in production of consumer products, as they are light, durable, resistant to corrosion by most chemicals, diversity of applications, ease to processing and low cost. Other than the mentioned advantages of plastics, studies have shown that plastic-based products are responsible for reduction in cost of production in different fields of human endeavor [9].

Plastics are produced in large quantities due to the high demand of their use in agriculture, households, automobiles, packing materials, toys, electronics, and a variety of other applications [10]. Plastics are basically long hydrocarbon chained organic compounds synthesized from petroleum products.

They have become highly popular in short time because of their unmatched usability, wide range of application, non-degradable nature and low cost. As per the estimate given by Plastic Europe, the global production of plastic has crossed 280 million tones in 2011 and it is increasing exponentially [11]. The ever increasing demand for plastic has also produced a huge amount of plastic waste and they pose a serious threat to the environment because of their disposal problems[12]. A survey report of the Central Pollution Control Board, India in 2012 shows nearly 5.6 million tones of plastic waste is generated annually in India. Out of this only up to $60 \%$ is recycled that means an astounding 6500 tones of plastic waste is going as landfills per day.

In order to minimize the adverse environmental impacts, Plastic Waste Management was implemented for controlling and reducing the plastic waste generated [13].The increase in plastics use correspondingly increases the amount of plastic wastes being produced. Plastic waste can be classified into at least two categories: municipal and industrial [14]. Industrial plastics are generally more homogeneous and contamination free, making them useful for down cycling into lower-grade plastic products.

Municipal plastics tend to be more heterogeneous and contain extraneous materials. In general, about 10.6 $\pm 5.1 \mathrm{wt} \%$ of municipal wastes consists of plastics [15]. Municipal plastic waste consists primarily of lowdensity polyethylene (LDPE), high-density polyethylene (HDPE), poly(ethylene terephthalate) (PET), polypropylene (PP), poly-styrene (PS), and poly(vinylchloride) (PVC) [14].

Overall, about $50-70 \%$ of the total plastic waste is packaging materials derived from polyethylene, polypropylene, polystyrene, and polyvinylchloride [16]. On average, polyethylene makes up the greatest fraction of all plastic wastes (69\%), especially plastic bags [15], and polyethylene comprises $63 \%$ of the total packaging waste [16].

\section{Environment Global Issues}

Plastic solid waste is a major contributing factor towards the waste generated on a global level. Disposal of polymer is becoming a global issue due to high production and consumption of polymer materials [17]. Many countries have their different waste generation level based on their income level become a serious issue for disposal and management of PSW. Management of waste is a complex process because of the requirement of various information from different sources such as influencing factors in waste generation, forecasts of vast quantities and reliable data [18]. In Eastern and Central Asia, the waste generated per year is at least 93 million tones. The per capita waste generation ranges from 0.29 to $2.1 \mathrm{~kg}$ per person per day, with an average of 1.1 $\mathrm{kg} / \mathrm{capita} / \mathrm{day}[19]$.

Solid waste management contributes less than $5 \%$ of global greenhouse gas (GHG) emission[20]. In response to growing concerns about the threat of climate change, international action aimed at reducing greenhouse gas (GHG) emissions is accelerating and the solid waste management sector is expected to contribute [21]. Land filling leads to contamination of earth's surface. Further, land filling leads to emission of carbon dioxide gas. Plastic also contributes towards the health related issues like Skin corrosion/irritation, Aspiration hazard, serious eye damage/eye irritation etc. It takes much time for polymerization reactions to complete and, therefore, unreacted residual monomers often found in the polymeric material, many of which are hazardous to human health and the environment [22].

Plastic disposal is a major concern in many countries, including the United State. After its initial use, over $60 \%$ of the total plastic solid waste (PSW) produced is discarded in landfills throughout the world [15]. Less than $10 \%$ of plastic waste is recycled. This is problematic, as plastic waste is a major environmental threat due to its non-degradability[23], its potential health risks to aquatic and terrestrial animals [24], and its impact on environmental pollution[22]. The waste plastics ending up in ocean makes a huge plastic soup and garbage patch like the great Pacific garbage patch risking the health of aquatic animals. In the last 40 years the plastic waste in the North Pacific ocean has increased by 100 -fold. The plastic foot- print is consider more dangerous than carbon footprint[10]. Some of the proposed solutions for PSW management are incineration or mechanical recycling. However, incineration can contribute to pollution by causing harmful and toxic emissions [25]. Additionally, both of these processes are costly and may or may not be economically viable in different situations[26].

Aside from the challenge of plastic waste disposal, another global issue is the energy crisis. Transportation consumes one third of the world's energy. The main energy sources for transportation are fossil fuels, coal, oil, and natural gas, all of which are non-renewable sources of energy. Fossil fuels are also major sources of environmental pollution, greenhouse gases, and ocean acidification [17,27]. 
Today, these fuels are being consumed at an unsustainably high rate throughout the world [26]. Even though more than a hundred billion tons of oil and gas have been discovered in the last 40 years [27], the rate at which it is consumed has also increased. The US alone consumes one quarter of the global oil supply, while only having $1.6 \%$ of the total oil reserve. At the current rate of consumption, the global supply of fossil fuels will be depleted within 40-70 years. Among 195 countries in the world, only 40 can produce fossil fuel, and for some countries, their independent oil reserve still do not satisfy all of their energy needs [17]. Many countries spend a significant portion of their gross national income (GNI) to purchase oil and gas. A number of studies have been conducted to investigate alternative ways of producing energy. Some of the alternatives for fossil fuel energy are biomass energy, wind energy, hydroelectric energy, and nuclear energy [12]. Biobased oils such as palm oil, soybean oil, corn oil, cottonseed oil and their derivatives are used as lubricants and fuel additives to replace petrochemicals [28]. However, even these additional energy sources may not completely solve the problem of increasing energy demand.

\section{Plastic Waste}

The increase in plastics use correspondingly increases the amount of plastic wastes being produced. Plastic waste can be classified into at least two categories: municipal and industrial [14]. Municipal plastic wastes (MSW) collected as household wastes, although normally remain a part of municipal solid wastes. The various sources of MSW plastics includes agricultural (like mulch films, feed bags, fertilizer bags, and in temporary tarpaulin-like uses such as covers for hay, silage, etc.), wire and cable, automobile wrecking, etc domestic items ( like food containers, packaging foam, disposable cups, plates, cutlery, CD and cassette boxes. fridge liners, vending cups electronic equipment cases, drainage pipe, carbonated drinks bottles, plumbing pipes and guttering, flooring. cushioning foams, thermal insulation foams, surface coatings, etc.), [26].

Separation of plastics from household wastes is required to recycle municipal plastic wastes. Mechanical separation equipment is currently available for separation mixed plastics [29]. For example, separating using a wet process mixed plastics can be separated into two groups: those with a density greater than water such as polystyrene and polyvinyl chloride, and those with a density lower than that of water such as polyethylene, polypropylene, and expanded polystyrene. The larger group is the latter group. Consequently, recycling of municipal plastic wastes should deal with plastic mixtures of polyethylene, polypropylene and polystyrene, proved that the above separation procedures are practiced. Although MSW separation technologies have been studied extensively, it is still not possible to obtain marketable fractions and classify MSW mechanically. So waste separation at the household would be a better option, and separately disposed into three parts: (i) combustibles such as paper, kitchen waste, textiles, and wood, (ii) incombustibles such as metals, glass, ceramics, and (iii) plastics [40].

Industrial plastic wastes (called primary Waste) are those arising from the large plastics manufacturing, processing and packaging industry. The industrial waste plastic mainly comes from construction and demolition companies (e.g. polyvinyl chloride pipes and fittings, tiles and sheets) electrical and electronics industries (e.g. switch boxes, cable sheaths, cassette boxes, TV screens, etc.) and the automotive industries spare-parts for cars, such as fan blades, seat coverings, battery containers and front grills). Most of the industrial plastic waste have relatively good physical characteristics i.e. they are clean enough in the production and there is no contamination and are available in sufficient quantities. During the manufacturing process it's use high temperatures which may have decreased its characteristics, but it has never been used to product applications [26]

Municipal plastic wastes are heterogeneous and industrial plastics wastes are homogeneous in nature. To recycling homogeneous plastic wastes can use repelletization and remolding, it's seem to be a simple and effective. But if plastic wastes are heterogeneous or consist of mixed resins, they are unsuitable for reclamation. In this case thermal cracking into hydrocarbons may provide a suitable means of recycling, which is termed chemical recycling [40].

The last 40 years have witnessed an explosive growth of the plastic industry. The production of synthetic polymers signified by polyethylene (PE), polypropylene (PP), polystyrene (PS), and polyvinyl chloride (PVC) worldwide has increased more than 100 times in the last four decades. These plastics are widely used in very important day to day applications such as fashion, household appliances and in automotive products and aerospace [23]. As there are various plastic based materials are available in the market or as waste. Two basic categories of plastic are designated as thermosetting (long strands) and thermoplastic (short link) materials. Thermosetting plastic materials are those which cannot be recycled again and thermoplastic are those which have certain recycling capacity [30].

The treatment of waste plastics becomes an unavoidable circumstances and imminent issue. In this regard, it can be safely stated that urgent effective ways to recycle waste plastics. Recently new ways of environmentally-friendly waste plastic recycling have been of interest, and among them, the use of waste plastics as a supplemental fuel with coal in the steel making industry has attracted interest Attention is also focused on using oil derived from waste plastics in diesel engines. Diesel engines are the most preferred power plants due to their excellent drivability and higher thermal efficiency [23].

Plastics are non-biodegradable polymers mostly containing carbon, hydrogen and few other elements. According to a nationwide survey conducted in India in the year 2000 approximately $6000 \mathrm{t}$ of plastic wastes were generated every day, and only $60 \%$ of it was 
recycled. In India alone, the demand for plastics is about 8 million tons per year. More than 10,000 metric tons/ day are produced in India and balance is imported from other countries. Most of the plastics are recycled and sometimes it is not done so due to lack of sufficient market value. Of the waste plastics not recycled about $43 \%$ is polyethylene and most of them is in the form of containers and packaging materials. The extent of conversion of plastics or plastic derived waxes into light engine fuels can be increased by the application of stable hydro cracking catalysts. Similar to petroleum derived cracking products, the fractions from plastics processing contain appreciable quantities of aromatics and unsaturated hydrocarbons [29].

\section{Production of Fuel from Plastic}

The challenges of plastic waste management and increasing energy demand can simultaneously be addressed by the production of fuel from plastics, and a number of research groups are currently developing this capacity. The fuels produced from plastics can be clean and have fuel properties similar to fossil fuels [31]. HDPE, LDPE, and PP are polymers containing only carbon and hydrogen. Unlike bio-fuels, the absence of oxygen and higher carbon and hydrogen content in plastic fuels avoids the need of further upgrading. The absence of water in plastic fuels makes the caloric value very high, and the absence of oxygen content makes the fuel non-acidic and non-corrosive, unlike bi-ofuel[3133]. Therefore, conversion of these plastic wastes to usable oil is a growing and important field of study that can potentially mitigate the energy crisis. However, the techno-economic evaluation plays an important role in the commercial success of the plastics to fuel conversion.

The production of fuel from plastics is one of the most demanding research topics throughout the world. Thermo chemical, and catalytic conversion are the most widely used methods for fuel production from plastics [26]. Among them, thermo chemical conversion/pyrolysis treatment seems to be the dominant mode used.

\subsection{Thermo chemical}

Thermo chemical treatment breaks large polymers into smaller hydrocarbons of various carbon numbers and boiling points in an inert, air-free, or controlled environment at elevated temperature [13]. The hydrocarbons between the boiling points of 35 and 185 ${ }^{\circ} \mathrm{C}$ can be used as motor gasoline, between 185 and 290 ${ }^{\circ} \mathrm{C}$ as diesel \#1, between 290 and $350{ }^{\circ} \mathrm{C}$ as diesel \#2, between 350 and $538{ }^{\circ} \mathrm{C}$ as vacuum gas oil, and 4538 ${ }^{\circ} \mathrm{C}$ as the residue [31]. These fractions can be obtained in different proportions by the appropriate choice of thermal treatment/degradation temperature, type of plastics, degradation time, and catalyst type [33-35].

The product yields of liquid, gas, and residue vary depending on the type of polymer, degradation temperature, and atmosphere. Some data on product yields obtained for thermal treatments at $400-800{ }^{\circ} \mathrm{C}$. Although the results vary somewhat because they come from different studies, thermo-chemical treatment seems to be a promising method of producing hydrocarbons from polymers. A subset of the thermal treatment is the gasification process. In this case the plastic is decomposed to combustible gaseous products at high temperatures, usually with the help of an oxidizing or a gasification agent. Both of these techniques to convert plastics to fuel do not have negative impacts on the environment [36,37].

\subsection{Catalytic conversion}

In catalytic conversion, catalysts are added to pyrolysis reactions to improve conversion, improve fuel quality, increase selectivity, and lower the pyrolysis temperature and residence time [13]. Pyrolysis is generally defined as the controlled burning or heating of a material in the absence of oxygen. In plastics pyrolysis,

the macromolecular structures of polymers are broken down into smaller molecules or oligomers and sometimes monomeric units. Further degradation of these subsequent molecules depends on a number of different conditions including (and not limited to) temperature, residence time, and the presence of catalysts and other process conditions. The pyrolysis reaction can be carried out with or without the presence of catalyst. Accordingly, the reaction will be thermal and catalytic pyrolysis. Since majority of plastic used are polyolefins, so extensive research has been done on this polymer which is summarised as below [26].

\subsubsection{Thermal pyrolysis}

The non-catalytic or thermal pyrolysis of polyolefins is a high energy, endothermic process requiring temperatures of at least 350-500 8C [42,43]. In some studies, temperatures as high as $700-9008 \mathrm{C}$ are essential in achieving decent product yields [44,45]. Thermal pyrolysis of both virgin and waste plastics as well as other hydro-carbonaceous sources has been studied extensively in the past. A good number of these thermal cracking studies are on polyethylene, polystyrene, and polypropylene[42,45]. On the other hand, only a few have worked on the thermal decomposition of other common plastics. Generally, thermal cracking results in liquids with low octane value and higher residue contents at moderate temperatures, thus an inefficient process for producing gasoline range fuels [42].

The gaseous products obtained by thermal pyrolysis are not suitable for use as fuel products, requiring further refining to be upgraded to useable fuel products $[46,47]$. A few researchers have sought to improve thermal pyrolysis of waste polyolefins without employing the use of catalysts; however these changes either yielded insignificant improvements or added another level of complexity and costs to the system [48]. 


\subsection{Catalytic cracking}

Addition of catalyst enhances the conversion and fuel quality. As compared to the purely thermal pyrolysis, the addition of catalyst in polyolefin pyrolysis [26].

1. Significantly lowers pyrolysis temperatures and time. A significant reduction in the degradation temperature and reaction time under catalytic conditions results in an increase in the conversion rates for a wide range of polymers at much lower temperatures than with thermal pyrolysis.

2. Narrows and provides better control over the hydrocarbon products distribution in Low density polyethylene (LDPE), High density polyethylene (HDPE), polypropylene and polystyrene pyrolysis. Again, oils obtained by catalytic pyrolysis contain less olefins and more branched hydrocarbon and aromatic content.

3. Increases the gaseous product yields. Under similar temperatures and reaction times, a much higher gaseous product yield is observed in the presence of a catalyst for polyethylene.

Catalytic degradation of plastics is found to have greatest potential to be developed into a commercialized process [49]. One of the most successful example being the Alka Zadgaonkar's Unique Waste Plastic Management \& Research Company plant in India which could produce fuel oil from waste plastics at par with the regular gasoline. From the research, it is clear that the oil produced in this process resembles the regular petrol in all respects (from color until reactivity with heavy metal) and reported to give better mileage as compared to commercial petrol. In addition, the cost of production is also reported to be very less.

\section{Conclusion}

The utilization of plastic waste cannot reduced landfill waste significantly, but most of the plastic waste can definitely produced may be treated with suitably process method to produce fossil fuel substitutes. The method should be superior in all respects (ecological and economical). Fuel production from plastics is attractive because it simultaneously addresses the issues of waste management and alternative energy generation. The optimization of conversion parameters such as the choice of catalysts, pyrolysis temperature, and plastic-to-catalyst ratio plays a very important role in the efficient processing of gasoline and diesel grade fuel. The use of a catalyst for thermal conversion lowers the energy required for conversion, and catalyst choice is important for efficient fuel production.

So, a suitable process which can convert waste plastic to hydrocarbon fuel if designed and implemented then that would be a cheaper partial substitute of the petroleum without emitting any pollutants

\section{Reference}

1. RAD. Arancon, CSK. Lin, KM. Chan, TH.Kwan, R.Luque. Energy SciEng1:53-71. (2013)

2. CSK. Lin, LA. Pfaltzgraff, L.Herrero-Davila, EB. Mubofu, S. Abderrahim, JH. Clark, et al. Energy Environ Sc;6:426-64 (2013)

3. L. Matsakas, U. Rova, P. Christakopoulos. BioResources;11:5482-99. (2016)

4. TPT. Pham, R. Kaushik, GK. Parshetti, R. Mahmood, R. Balasubramanian, Waste Manage; 38:399-408. (2015)

5. E. Svensson Myrin, PE. Persson, S. Jansson. Fuel ;132:165- 9. (2014)

6. Y. Qu, O. Zhu, J. Sarkis, Y. Geng, Y. Zhong. $J$ Clean Prod.;17 :1175-82. (2013)

7. Bupe G Mwanzaa, Charles Mbohwab. Procedia Manufacturing 8.649 - 656. (2017)

8. M.P. Subramanian, Conservation and Recycling 28, 253-263. (2000)

9. D. Hoornweg, P. Bhada-Tata, The World Bank; (2012).

10. F. Pinto, P. Costa, I. Gulyurtlu, CabritaI. J Anal Appl Pyrolysis; 51(1- 2):39-55. (1999)

11. Sriningsih, Wiwin, Saerodji, Monica Garby, Trisunaryanti, Wega, Triyono, Armunanto, Ria, Falah, lip Izul, Procedia Environ. Sci. 20, 215-224. (2014)

12. Antony, Raja, Advaith, Murali,. J. Mater. Sci. Eng. B1, 86-89. (2011)

13. AK. Panda, RK. Singh, DK. Mishra. Renew Sustain Energy Rev; 14 (1):233-48.(2010)

14. C. Zhou, W. Fang, W. Xu, A. Cao, R. Wang. Characteristics and the recovery potential of plastic wastes obtained from landfill mining; 80:806.(2014)

15. P. Lettieri, S. Al-Salem, Thermochemical treatment of plastic solid waste. In: Letcher TM,ValleroD, editors.Waste :A handbook for management; p. 233-42.(2011)

16. DS. Scott, SR. Czernik, J. Piskorz, DSAG. Radlein. Energy Fuels. ;4(4):407-11.(1990)

17. M. Sarker, M. M. Rashid, S. Rahman, M. Molla, Conversion of Low Density Polyethylene ( LDPE ) and Polypropylene ( PP ) Waste Plastics into Liquid Fuel Using Thermal Cracking Process 2(1), 1-11. (2012)

18. [18] D. Grazhdani, Waste Management 48, 3-13.(2016)

19. OECD, Global forum on environment focusing on sustainable materials. A material case study. (2010)

20. J. Bogner, M. Abdelrafie Ahmed, C. Diaz, A. Faaij, Q. Gao, S. Hashimoto, et al., 2007. Waste management. In: Metz, B., Davidson, O.R., Boesch, P.R., Dave, R., Meyer, L.A. (Eds.), Climate Change 2007: Mitigation Contribution of Working Group III to the Fourth Assessment Report of the International Panel on Climate Change. Cambridge University Press, Cambridge, UK . (2007) 
21. D. A. Turner, I. D. Williams, S. Kemp, Resources, Conservation and Recycling, 105, 186-197. (2015)

22. Matlack AS. Introduction to green chemistry. New York: Marcel Decker Inc; (2001).

23. PT. Williams, E. Slaney. Resour Conserv Recycl;51 (4):754-69.(2007)

24. RC. Thompson, SH.Swan, CJ.Moore, FSV. Saal. Our plastic age. Philos Trans R Soc B;364(1526):1973-6.(2009)

25. J. Aguado, DP. Serrano, JM Escola, Ind Eng Chem Res;47(21):7982-92.(2008)

26. FJ. Passamonti, U. Sedran. Appl Catal B: Environ;125:499-506. (2012)

27. NA. Owen, OR. Inderwildi, DA. King, Energy Policy; 38(8):4743-9.(2010)

28. SZ. Erhan, BK. Sharma, JM. Perez. Ind Crops Prod; 24(3):292-9.(2006)

29. Plastic Wastes: Resource Recovery and Recycling in Japan. Tokyo: Plastic Waste Management Institute; 1985

30. L. Gu, T. Ozbakkaloglu, 2016. Use of recycled plastics in concrete: A critical review. Waste Management. Vu P, Nishida O, Fujita H, Harano W. Reduction of NOx and PM from diesel engines by WPD emulsified fuel. SAE Tech Pap;1:0152. (2001)

31. BK. Sharma, BR. Moser, KE. Vermillion, KM. Doll, N. Rajagopalan. Fuel Process Technol; 122:79-90.(2014)

32. N. Miskolczi, A. Angyal, L. Bartha, I. Valkai, Fuel ProcessTechnol; 90(7-8):1032-40. (2009)

33. G. Elude, M. Olazar, G. Lopez, M. Amutio, M. Artetxe, R. Aguado, J. Bilbao. J Anal Appl Pyrolysis; 85(1-2):345-51.(2009)

34. M. Syamsiro, H. Saptoadi, T. Norsujianto, P. Noviasri, S. Cheng, Z. Alimuddin, K. Yoshikawa. Energy Procedia;47:180-8.(2014)

35. S. Kumar, R. Prakash, S. Murugan, RK. Singh, Energy Convers Manag;74:323-31. (2013)
36. G. BelgiornoV De Feo, C. Della Rocca, RMA. Napoli, Waste Manag; 23(1):1-15.(2003)

37. RP. Singh, VV. Tyagi, T. Allen, MH. Ibrahim, R. Kothari, Renew Sustain Energy Rev; 15(9):4797808.(2011)

38. K. Murata, K. Sato, Y. Sakata, Journal of Analytical and Applied Pyrolysis; 71(2): 569-89 (2004)

39. L. Sorum, MG. Gronli, JE. Hustad. Fuel; 80(9):1217-27. (2001)

40. A. Demirbas, Journal of Analytical and Applied Pyrolysis ;72:97-102. (2004)

41. FJ. Mastral, E. Esperanza, P. Garc1'a, M. Juste. Journal of Analytical and Applied Pyrolysis; 63(1):1-15. (2002)

42. SS. Kim, S. Kim. Chemical Engineering Journal; 98(1-2):53-60. (2004)

43. OS. Woo, N. Ayala, LJ. Broadbelt. Catalysis Today ; 55(1-2):161-71. (2000).

44. OS. Woo, LJ. Broadbelt, Catalysis Today; 40:12140. (1998).

45. JH. Chan, ST. Balke. Polymer Degradation and Stability; 57(2):135-49. (1997).

46. AR. Songip, Applied Catalysis B Environmental; 2(2-3):153-64. (1993).

47. HS. Joo, JA. Guin. Continuous upgrading of a plastics pyrolysis liquid to an environmentally favorable

48. DP. Serrano, J. Aguado, M. Escola, E. Garagorri, Applied Catalysis B Environmental;44(2):95-105. (2003).

49. Y. Sakata, MA. Uddin, A. Muto. Journal of Analytical and Applied Pyrolysis;51(1-2):135-55. (1999)

50. Alka Zadgaonkar. Conversion of Waste Plastic into Liquid Hydrocarbons/Energy-A major breakthrough in the arena of non-conventional sources of energy, Information Brochure and Technical Write-Up. 